\title{
Familiarity increases aggressiveness among clonal fish
}

Carolina Doran (1) https://orcid.org/0000-0002-7814-4675, David Bierbach (10) https://orcid.org/0000-0001-7049-2299, Kate L. Laskowski 1 https://orcid.org/0000-0003-1523-9340

DOI

10.1016/i.anbehav.2018.12.013

Original publication date

23 January 2019 (Available online)

Document version

Accepted manuscript

Published in

Animal Behaviour

Citation

Doran C, Bierbach D, Laskowski KL. Familiarity increases aggressiveness among clonal fish. Animal Behaviour. 2019;148:153-9. 
1 Familiarity increases aggressiveness among clonal fish.

2 Carolina Doran $^{1^{*}}$, David Bierbach ${ }^{1}$ and Kate L. Laskowski ${ }^{1}$

31 - Department of Biology and Ecology of Fishes, Leibniz-Institute of Freshwater Ecology and

4 Inland Fisheries, Berlin, Germany.

5 *Corresponding author: carolina.doran@gmail.com

\section{Abstract:}

7 Understanding how animal groups form and function is a major goal in behavioural ecology.

8 Both genetic relatedness and familiarity among group mates have been shown to be key

9 mediators of group composition. However, disentangling the two in most species is

10 challenging as the most familiar individuals are often the most related, and vice versa. But

11 whereas the relatedness between individuals is constant, familiarity is not, and so familiarity

12 may be more likely to mediate interactions in dynamic environments. Here, we manipulated

13 the level of familiarity among groups of the naturally clonal, and genetically identical fish,

14 the Amazon molly (Poecilia formosa) and monitored group behaviour in an open-field and

15 when given the opportunity to forage. Contrary to our predictions, fish that were the most

16 familiar with each other showed the highest levels of aggression. Additionally, fish that were

17 less familiar with each other exhibited the highest group cohesion and took the longest to

18 begin feeding, compared to the more familiar fish. These results suggest that familiarity may

19 socially buffer individuals from the perception of risk in novel environments, such as is

20 common in most behavioural tests designed to test group behaviour. Increases in aggression

21 that are associated with increasing familiarity as shown here might be a mechanism by 
22 which fish maintain a fission-fusion society with important consequences for the patterns of

23 associations in group living animals.

24 Key words: Amazon molly, clonal, Genetic relatedness, group behaviour, Familiarity.

\section{Introduction}

27 Animals living in groups must balance the potential benefits of group living, such as greater 28 foraging efficiency, against the costs, such as increased aggression and competition 29 (Hamilton, 1971; Krause \& Ruxton, 2002). For example, fish in shoals benefit from being able 30 to better sense their local environment and have a higher probability of encountering food, 31 proportional to the size of the group (Berdahl, Torney, Ioannou, Faria, \& Couzin, 2013;

32 Magurran \& Pitcher, 1987; Peuhkuri, 1997). However group living also incurs costs, such as 33 competition over resources. Thus there is a trade-off between the costs and benefits of 34 group living, particularly when it comes to food exploitation (Conradt \& Roper, 2005; Ranta 35 \& Lindström, 1990; Reader, 2014). Individuals often mediate this trade-off by preferentially 36 associating with related and/or familiar individuals (Lee-Jenkins \& Godin, 2013; Thünken, 37 Hesse, Bakker, \& Baldauf, 2016; Ward \& Hart, 2003). However, these patterns of social 38 interactions can be complicated by the fact that animal groups often experience high group 39 turnover meaning individuals have to constantly adjust their behaviour to that of new 40 members (Couzin, 2006).

42 among these individuals can vary in response to several factors. Fish, for instance, are known 43 to alter their nearest neighbour distance in response to the presence of a predator or food 
44 (Hoare, Krause, Peuhkuri, \& Godin, 2000; Sogard, 1997). Furthermore, fish often switch

45 between shoals for any number of reasons, such as phenotypic assortment, differences in

46 swimming speed, or because individuals within the group have conflicting information about

47 the current state of the environment (Croft et al., 2005; Killen, Marras, Nadler, \& Domenici,

48 2017; Krause, Reeves, \& Hoare, 1998; Merkle, Sigaud, \& Fortin, 2015). In these fission-fusion

49 societies, the patterns of social encounters among individuals are very dynamic, with

50 important implications for the transmission of diseases and flow of information (Aureli et al.,

51 2008; Couzin, 2006; Krause \& Ruxton, 2002). These repeated associations will in turn affect

52 the degree of familiarity both among and within groups (Griffiths, 2003; Griffiths \&

53 Magurran, 1999; Lee-Jenkins \& Godin, 2013; Utne-Palm \& Hart, 2000; Ward \& Hart, 2003).

54 Understanding how and why individuals associate with each other can give insight into how

55 groups may evolve and function.

According to kin selection, genetic relatedness amongst individuals should facilitate

57 cooperation and reduce competition thus contributing to the evolution of group living

58 (Hamilton, 1964). Genetic relatedness has been shown to increase cooperation and

59 individual fitness (Gerlach, Hodgins-Davis, MacDonald, \& Hannah, 2007; Hesse, Anaya-Rojas,

60 Frommen, \& Thünken, 2015; Thünken et al., 2016). Familiarity seems to further contribute

61 to the effects of kinship by further enhancing cooperation among familiar group mates

62 (Griffiths \& Magurran, 1999; Lee-Jenkins \& Godin, 2013). Several studies show how fish

63 shoaling with familiar conspecifics tend to profit more from social learning, experience less

64 aggression, find food faster and eat more than groups composed of unfamiliar individuals

65 (Berdahl et al., 2013; Swaney, Kendal, Capon, Brown, \& Laland, 2001; Utne-Palm \& Hart,

66 2000). Associating with familiar individuals also appears to increase the anti-predator and 
67 foraging benefits of schooling behaviour (Chivers, Brown, \& Smith, 1995; Metcalfe \& 68 Thomson, 1995; Pitcher, Magurran, \& Edwards, 1985; Utne-Palm \& Hart, 2000). However, 69 the ecological context, a group is experiencing at any given moment, will influence whether 70 both familiarity and/or kinship are beneficial or not (Frommen et al., 2012; Kelley, Graves, \& 71 Magurran, 1999; West, Pen, \& Griffin, 2002). For example, when it comes to mating, male 72 guppies prefer familiar female partners (Kelley et al., 1999), however in a foraging scenario 73 sticking with familiar individuals might render the groups foraging strategy easily 74 recognisable and thus exploitable by outsiders (Ward \& Hart, 2005).

A major step towards understanding the formation and function of groups relies on the ability to successfully disentangle familiarity and kinship which can be challenging in 77 many species (Lee-Jenkins \& Godin, 2013). Importantly, whereas kin relationships are constant, familiarity among group members is not. This suggests that among species with dynamic social interactions, familiarity may play an especially important role in determining social associations and therefore group behaviour. Here we take advantage of a unique species to test the influence of familiarity on group behaviour while holding relatedness constant. We used the naturally clonal fish, the Amazon molly (Poecilia formosa), a small live-bearing freshwater fish that produces broods of genetically identical offspring allowing 84 us to isolate and test the role of familiarity on group dynamics. We compared aspects of 85 group behaviour, such as aggressive interactions, group cohesion and resource defence 86 among groups of mollies that differed in their level of familiarity. There is reason to believe 87 that familiarity plays a major role in the group dynamics of the Amazon molly. These social 88 fish form large groups in the wild where they forage and compete for resources together 89 (Ingo Schlupp, Parzefall, \& Schartl, 2002). Previous work has already demonstrated that 
90 relatedness among individuals modulates their level of aggression with less

91 related(Makowicz, Tiedemann, Steele, \& Schlupp, 2016; I Schlupp, 2009). P. formosa are

92 known to be aggressive and form stable dominance hierarchies (Makowicz \& Schlupp, 2015)

93 so we predicted that groups that were more familiar with each other would stabilise sooner

94 and show a decrease in aggression and resource defence (i.e. more egalitarian distribution of

95 feeding). Furthermore, we also predicted that this pattern would be accompanied by an

96 increase in group cohesion.

\section{Methods:}

98 The Amazon molly:

99 This live-bearing, freshwater fish originated through a hybridization event between the

100 Sailfin molly (Poecilia latipinna) and the Atlantic molly (Poecilia mexicana) an estimated

101 100,000 years ago (Warren et al., 2018) and now reproduces through gynogenesis (Parzefall,

102 1989). This means that females require sperm from a male of one of the parental species ( $P$.

103 latipinna, P. mexicana) in order to induce embryogenesis, but do not incorporate the 104 paternal genetic content (Schartl, Wilde, Schlupp, \& Parzefall, 1995).

105 Fish husbandry:

106 Prior to the experiment, fish were maintained as part of our laboratory populations in $100 \mathrm{~L}$

107 stock tanks and fed ad libitum two times daily on standard flake food with a constant 108 temperature of $25^{\circ} \mathrm{C}$. Tanks were cleaned and $50 \%$ of the water volume was exchanged 109 weekly. The population of $P$. formosa used for this study were obtained from Manfred 110 Schartl, University of Würzburg. Since Amazon mollies reproduce gynogenetically and 111 females require the sperm from one of their parental species in order to induce 
112 embryogenesis each stock tank also contained several male $P$. mexicana. We used a strain of

113 P. formosa that has been kept in captivity since 2002 and regular molecular checks confirm

114 that individuals are clones (M. Schartl 2015, personal communication)

115 Familiarity manipulation \& group behaviour assays:

116 We generated three treatment groups with mollies that had lived together for differing

117 amounts of time. After this familiarity manipulation we measured their behavior in two

118 different contexts: both before and after the addition of a defendable food resource.

We collected 96 individuals from our laboratory population, assembling groups of 4

121 individuals each in 24 smaller housing tanks $(40 \times 20 \times 20 \mathrm{~cm} ; 8$ groups/housing tanks per each

122 treatment). We used only adult individuals and size-matched individuals within groups

123 (range: $4.40-8.11 \mathrm{~cm}$; mean $=6.14 \pm \mathrm{SD}=0.76$ ). Individuals were placed into these housing

124 tanks to standardize social experience prior to having their behaviour observed (see below).

127 the housing tanks; what differed was the identity of their group mates in the housing tanks

128 and how long they have lived with these group mates prior to behavioural assessment 1, 7

129 or 21 days respectively (Figure 1). To assemble a treatment group, one individual from four

130 of the assigned housing tanks was haphazardly removed, and these individuals were placed

131 in a new housing tank. For the low familiarity fish, this was done the day before behavioural

132 observations (i.e. 1 day of familiarity prior to testing); for the mid familiarity fish this was

133 done 7 days before observations and the high familiarity fish were kept together in the same 
134 housing tank for the entire 21 days. This experimental design would create differences in the 135 timeline of when the fish are physically handled; i.e. low familiarity fish are handled the day 136 before observations, whereas mid familiarity fish had 7 days to recover from the handling 137 prior to observations. To account for this, all fish were handled at the same time points as 138 the other treatments were being assembled (e.g. low familiarity fish were handled at week 2 139 to mimic the assembling process being done in the mid familiarity fish, see Figure 1 for 140 schematic details). This involved all fish in the housing tank being netted and held out of the 141 tank for several seconds and then returned to their tank. This process ensured that all 142 groups received the same amount and schedule of handling regardless of treatment; the 143 only difference among treatments should thus be the identity of their group mates.

We started with 24 groups of 4 individuals ( 8 groups per treatment) but due to a video malfunction we lost the data corresponding to one group (Mid familiarity treatment). 146 Finally due to natural mortality there were 3 groups with 3 individuals ( 1 in the high 147 familiarity and 2 in the low familiarity treatment). Our final sample size was 20 groups of 4 148 individuals and 3 groups of 3 individuals.

After this familiarization phase, groups were transferred into a large open-field observation arena $(60 \times 30 \times 30 \mathrm{~cm})$ with $5 \mathrm{~cm}$ deep water and allowed to acclimate overnight.

151 Open-field arenas provide a standardized way to measure behaviour in a novel environment 152 devoid of any obstruction (Walsh \& Cummins, 1976). We observed the behaviour of the fish 153 using an overhead webcam (Logitech C920 HD). The following morning, we observed the 154 baseline behaviour of the fish in the observation arena for 5 minutes. After this time, we 155 added a defensible food resource (sinking food tablet) and then observed the group for an 156 additional 5 minutes after at least one individual had started feeding at the tablet. We 
157 counted the total number of aggressive interactions (bites, chases and tail beats) performed 158 among group members (Bierbach et al., 2012; Foran \& Ryan, 1994; Heubel \& Plath, 2008), 159 and the median inter-individual distance among group members (extracted through video tracking using Ethovision XT12, Noldus Information Technology, Inc) both before and after

161 the addition of the food. After the food was added, we measured a number of foraging 162 behaviours: latency for the first individual to begin feeding, how long each individual spent 163 eating and the distribution of how many individuals were feeding simultaneously (i.e. one, 164 two, three or four individuals at the food tablet at the same time). Additionally, we identified 165 the dominant individual in each group as the individual who performed the majority of 166 aggressive encounters while receiving the fewest (Laskowski, Wolf, \& Bierbach, 2016). After 167 having identified the dominant individual, we also scored the amount of time it spent eating.

168 Finally, the collective duration of feeding was obtained by summing the duration of feeding 169 by every individual in the group. At the end of every trial a snapshot from the video was 170 taken to measure the standard length (in $\mathrm{cm}$ ) of each individual using ImageJ.

\section{Statistics:}

172 We tested how familiarity and context (before and after food) influenced group behaviour 173 using general linear mixed models. We ran separate models with the total number of 174 aggressive behaviours and inter-individual distance as our response variables. Both models 175 included the fixed effects of familiarity (low, mid, high) and context (before/after the food 176 was added) and an interaction between these two factors. We also included median body 177 size and body size variation within the group as a covariate and group as a random effect as 178 we had two measures from each group (across the two contexts). 
linear models with latency for the first individual to begin feeding and the total duration of

181 all individuals feeding (i.e. collective feeding), and the duration the dominant individual

182 spent eating as our response variables. These models included familiarity as a fixed effect

183 and both the median and variance of individual size within groups as a covariate; group was

184 not included as a random effect as these response variables only had one observation per

185 group.

We assumed a Gaussian error distribution for all models and we visually confirmed that our residuals met model assumptions (see figures in SM). To test the overall significance of the fixed effects in our mixed models we compared the log-likelihood ratio of a model that contained the effect of interest, to one that did not. In order to obtain the amount of variation explained by each model we additionally estimated both the marginal and conditional R-squared value according to (Nakagawa \& Schielzeth, 2013). The marginal Rsquared estimates how much variation was explained by the fixed factors whereas the conditional R-squared estimates the variation explained by both fixed and random factors together.

Finally, in order to test for differences in the number of animals feeding simultaneously we ran a chi-square test with the number of seconds there were one, two, three or four, individuals eating (for this test only groups of 4 individuals were counted). All statistics were run in R v3.4.4, using packages nlme and Ime4 for linear and mixed models 199 and ggplots and ggplot2 for plotting (Bates, Maechler, Bolker, \& Walker, 2015; Pinheiro, 200 Bates, DebRoy, \& Sarkar, 2018). The R script of the entire statistical analysis and the raw 201 data can be found in the supplementary material. 
203 This research was conducted in accordance with the ASAB/ABS guidelines for the use of

204 Animals in Research. During the experiment there was always an observer present to 205 determine whether the aggressive interactions resulted in physical damage to the fish. 206 Should that occur experiments would have immediately stopped. Every individual was 207 closely monitored both before and after each trial to ensure there was no indication of 208 physical harm and fish resumed normal feeding and behaviour upon return to their stock 209 tanks. The number of experimental animals used was the minimum necessary for the 210 statistical testing and was based in previously published studies (Griffiths \& Magurran, 1997;

211 Kelley et al., 1999; Swaney et al., 2001). Finally, experimental animals were afterwards 212 integrated into our stocks and served for breeding. They have not been used for any further 213 experiments.

214 The reported experiments comply with current German law approved by LaGeSo 215 Berlin (GO124/14 to D.B.).

216 Results:

217 Aggression:

218 Contrary to our predictions, we found that aggressive interactions significantly increased 219 with familiarity in a clonal fish (table 1, significant effect of familiarity). We also found that 220 aggression was higher before the food was added compared to after (table 1, significant 221 effect of context). Interestingly, in the mid-familiarity treatment, the decrease in aggression 222 after the food was added appears to be the strongest compared to the other two familiarity 223 treatments (Figure 2), though this effect was not strictly significant (table 1, non-significant 
224 interaction.). Finally neither individual size nor size variation within groups significantly

225 affected the level of aggression (Table 1).

226 Feeding behaviour:

227 Again, contrary to our predictions, the collective duration of feeding was not affected by

228 familiarity (Treatment $F_{18,20}=1.8912, P=0.1797$ ). However, the time taken for the first 229 individual to start feeding after the addition of food significantly decreased with familiarity 230 (Treatment $F_{18,20}=5.737, P=0.0118$ ). That is, in the high familiarity groups, fish began to 231 feed faster. The amount of time the dominant fish of each group spent eating was not 232 affected by treatment (Treatment $F_{18,20}=0.1988, P=0.8215$ ). Rather, the distribution of 233 feeding, (i.e. how many individuals were eating at the same time within each group) was 234 significantly different for each of the treatments $\left(X^{2}=38087\right.$, df $=8$ and $\left.P<0.001\right)$, with 235 more individuals feeding simultaneously when familiarity was low (Fig. 3). Finally, median 236 body size and body size variation within groups did not significantly influence any measure 237 of feeding behaviour (Collective feeding: Fish Size $F_{18,19}=1.4077, P=0.2509$; Fish var $F_{18,19}=$ $2382.5045, P=0.1309$; Latency to begin feeding: Fish Size $F_{18,19}=1.3289, P=0.2641$, Fish var $239 F_{18,19}=0.2578, P=0.6178$; Dominant fish feeding duration: Fish Size $F_{18,19}=0.2531, P=$ 240 0.621, Fish Var $F_{18,19}=1.4243, P=0.2482$ )

241 Group behaviour:

242 Finally, also contrary to our initial prediction, increasing familiarity within groups led to 243 decreases in group cohesion as measured by inter-individual distance (table 2, significant 244 effect of treatment). Cohesion increased after food was added (table 2, significant effect of 245 context) and this was independent of the familiarity treatment (non-significant interaction 
between treatment and context, Figure 4, Table 2). Median body size had no effect but

247 variation in body size was marginally significant (Table 2, effect of Fish var).

\section{Discussion}

249 A critical step towards understanding the formation of social associations in animal groups 250 relies on the ability to disentangle the roles of familiarity and kinship. Kin selection tells us 251 how genetic relatedness is at the core of the evolution of group living with several studies 252 suggesting how familiarity adds to this effect (Griffiths \& Magurran, 1999; Hamilton, 1964; 253 Lee-Jenkins \& Godin, 2013). But how does group behaviour differ based on familiarity alone? 254 By exploiting a unique animal system, the clonal Amazon molly (Poecilia formosa), we were 255 able to isolate the effects of familiarity on the behaviour of fish groups. We show that, contrary to our predictions, familiarity significantly increased the number of aggressive encounters accompanied by a decrease in group cohesion. potential mechanism driving the maintenance of fission-fusion societies. Social systems 260 characterized by fission-fusion dynamics are wide-spread in the animal kingdom not only in 261 schooling fish, like the Amazon molly, but also in bats, dolphins, elephants, hyenas and 262 several species of primates (Aureli et al., 2008; Connor, 2007; Kerth \& König, 1999; Smith, 263 Kolowski, Graham, Dawes, \& Holekamp, 2008; Wittemyer, Douglas-Hamilton, \& Getz, 2005). 264 Understanding the factors that mediate group formation is therefore at the forefront of 265 studies of animal collective behaviour. For example, in baboons both habitat structure and 266 social interactions significant influence group movement pattern (Strandburg-Peshkin, 267 Farine, Crofoot, \& Couzin, 2017). Furthermore, in bison, when individuals possess conflicting 
268 information regarding the location of a desired resource, groups often split (Merkle et al.,

269 2015). Finally separating from a group is often necessary due to the existence of high levels

270 of aggression, but this also needs to be carefully managed when joining a new group as

271 conflicts can also arise then (Aureli \& Schaffner, 2007). Our study highlights how internal

272 factors such as intra-group conflict may be just as important in mediating group formation

273 and dynamics as external factors such as resource availability and habitat structure.

Interestingly, the finding here that more familiar fish are more aggressive contradicts

275 several studies showing that, increasing familiarity within groups often decreases aggression

276 and increases group cohesion and food sharing (Chivers et al., 1995; Höjesjö, Johnsson,

277 Petersson, \& Järvi, 1998; Johnsson, 1997). There are a number of potential explanations for

278 this unexpected finding. Due to their unique type of reproduction, the unisexual Amazon

279 molly lives in mixed-species shoals together with their parental species $P$. latipinna and $P$.

280 mexicana, and also with different clonal lineages (I. Schlupp \& Ryan, 1996). Because these

281 fish require sperm from males of one of the parental species (Ingo Schlupp, Parzefall, \&

282 Schartl, 1991), Amazon mollies might display higher aggression as a strategy to increase

283 attractiveness and gain more access to males. Indeed, previous research has already shown

284 that $P$. formosa is more aggressive when compared to the parental species, and this

285 aggression increases over time. Makowicz et al (2015) suggest that individuals might have

286 low tolerance for consistent interactions with the same individuals, potentially because in

287 natural conditions, groups are very plastic with high group turnover rates. This increase in

288 aggression with familiarity may therefore provide one reason why so many fish species exist

289 as dynamic fission-fusion societies. 
291 of familiarity on the duration of time the group spent feeding as a whole. However, the 292 number of individuals feeding at any given time differed. The dominant individual was 293 always the one who spent the most time feeding, and this was not affected by familiarity. 294 But in less familiar groups, more individuals were able to feed simultaneously, however as 295 familiarity increased, the skew in individual feeding times increased until the dominant 296 individual essentially monopolized the resource. Interestingly, this is contrary to previous 297 work which found greater food sharing in more familiar groups (Utne-Palm \& Hart, 2000). It 298 is likely that the pattern of feeding in the Amazon mollies is driven by the increase in 299 aggression in more familiar groups: in low familiarity groups, aggression was lower and 300 group members had more opportunity to reach the food. Thus, individuals may be more 301 motivated to frequently change groups (and decrease familiarity) if this increases their 302 ability to access food resources. Another potential explanation for why less familiar fish show unexpectedly low 304 aggression is because of social buffering. Social buffering is the process by which social groups offer a safer environment in the presence of a perceived threat (Faustino, TacãoMonteiro, \& Oliveira, 2017; Hennessy, Hornschuh, Kaiser, \& Sachser, 2006). When familiarity 307 is low, being placed in a novel environment, such as the testing arena used here, might be 308 perceived as risky. Thus, individuals remain cohesive as a group with low levels of 309 aggression. Indeed, after the addition of the food, which required a necessary disturbance, 310 group cohesion in the low familiarity groups increased and individuals took the longest to 311 begin feeding, further suggesting they interpret this disturbance as a potential threat. For 312 example, in rats, the presence of a familiar conspecific is more effective in reducing an 
313 individual's response to a frightening stimulus than an unfamiliar conspecific (Kiyokawa, 314 Honda, Takeuchi, \& Mori, 2014). Here too, when individuals are more familiar with one 315 another, as is the case for the mid familiarity treatment, the scenario changes slightly. Then, 316 individuals exhibited lower group cohesion and higher aggression prior to the food being 317 added, but once the group is disturbed by the addition of the food, aggression decreases and 318 cohesion increases similar to what was seen in the low familiarity groups. Finally, three 319 weeks of familiarization in the highly familiarity groups appears to be sufficient to strongly 320 reduce any perceived risk by the introduction to the novel testing arena or the addition of 321 the food as aggression remained high and group cohesion low in these groups. Taken 322 together, our results suggest that familiarity mediates how the group responds to novelty, 323 through social buffering. Groups that are more familiar can cope better both with being in a

324 new environment and with the unexpected food delivery, and thus are able to maintain their 325 high levels of aggression. The fact that aggression increases with familiarity indicates that 326 individuals are no longer seeking safety in numbers but instead asserting their dominance 327 within their groups.

Our study provides new insight into potential mechanisms driving both the formation 329 and maintenance of fission-fusion dynamics. There is a long history investigating how 330 relatedness and familiarity may play a role in these processes. Here, we show that even 331 among genetically identical individuals, familiarity is sufficient to drive patterns of intra332 group conflict which could have consequences on group stability and dynamics.

\section{Competing interests:}

334 The authors declare no competing interests 
Both the raw data and analysis can be found in the supplementary material

\section{Acknowledgements:}

338 We thank David Lewis, Marcus Ebert and Juliane Lukas for help with animal care. We are 339 especially grateful to Hai Nguyen for his help with setting up the camera systems. 340 Furthermore, we thank Manfred Schartl (University of Würzburg) for providing us with 341 individuals of the Amazon molly. We received financial support from the Leibniz Competition 342 (SAW-2013-IGB-2) and from the DFG (BI 1828/2-1 (to DB); LA 3778/1-1 (to KLL). Finally CD 343 was supported by an AvH fellowship.

\section{Reference list:}

345 Aureli, F., \& Schaffner, C. M. (2007). Aggression and conflict management at fusion in spider 346 monkeys. Biology Letters, 3(2), 147-149. https://doi.org/10.1098/rsbl.2007.0041

347 Aureli, F., Schaffner, C. M., Boesch, C., Bearder, S. K., Call, J., Chapman, C. A., ... Schaik, C. P. van.

348 (2008). Fission-fusion dynamics: new research frameworks. Current Anthropology, 49(4), 627-654.

349 https://doi.org/10.1086/586708

350 Bates, D., Maechler, M., Bolker, B., \& Walker, S. (2015). Fitting Linear Mixed-Effects Models Using 351 Ime4. Journal of Statistical Software, 67(1), 1-48.

352 Berdahl, A., Torney, C. J., loannou, C. C., Faria, J. J., \& Couzin, I. D. (2013). Emergent sensing of 353 complex environments by mobile animal groups. Science, 339(6119), 574-576.

354 https://doi.org/10.1126/science.1225883

355 Bierbach, D., Klein, M., Sassmannshausen, V., Schlupp, I., Riesch, R., Parzefall, J., \& Plath, M. (2012).

356 Divergent evolution of male aggressive behaviour: another reproductive isolation barrier in 357 extremophile Poeciliid fishes? International Journal of Evolutionary Biology, 2012, 1-14.

358 https://doi.org/10.1155/2012/148745

359 Chivers, D. P., Brown, G. E., \& Smith, R. J. F. (1995). Familiarity and shoal cohesion in fathead 360 minnows (Pimephales promelas): implications for antipredator behaviour. Canadian Journal of 361 Zoology, 73(5), 955-960. https://doi.org/10.1139/z95-111 
Connor, R. C. (2007). Dolphin social intelligence: complex alliance relationships in bottlenose dolphins and a consideration of selective environments for extreme brain size evolution in mammals. Philosophical Transactions of the Royal Society B: Biological Sciences, 362(1480), 587-602. https://doi.org/10.1098/rstb.2006.1997

Conradt, L., \& Roper, T. J. (2005). Consensus decision making in animals. Trends in Ecology \& Evolution, 20(8), 449-456. https://doi.org/10.1016/j.tree.2005.05.008

Couzin, I. D. (2006). Behavioral ecology: social organization in fission-fusion societies. Current Biology, 16(5), R169-R171. https://doi.org/10.1016/j.cub.2006.02.042

Croft, D. P., James, R., Ward, A. J. W., Botham, M. S., Mawdsley, D., \& Krause, J. (2005). Assortative interactions and social networks in fish. Oecologia, 143(2), 211-219.

https://doi.org/10.1007/s00442-004-1796-8

Faustino, A. I., Tacão-Monteiro, A., \& Oliveira, R. F. (2017). Mechanisms of social buffering of fear in zebrafish. Scientific Reports, 7, 44329. https://doi.org/10.1038/srep44329

Foran, C. M., \& Ryan, M. J. (1994). Female-female competition in a unisexual/bisexual complex of mollies. Copeia, 1994(2), 504-508. https://doi.org/10.2307/1446999

Frommen, J. G., Zala, S. M., Raveh, S., Schaedelin, F. C., Wernisch, B., \& Hettyey, A. (2012). Investigating the effect of familiarity on kin recognition of three-spined stickleback (Gasterosteus aculeatus). Ethology, 119(6), 531-539. https://doi.org/10.1111/eth.12091

Gerlach, G., Hodgins-Davis, A., MacDonald, B., \& Hannah, R. C. (2007). Benefits of kin association: related and familiar zebrafish larvae Danio rerio show improved growth. Behavioral Ecology and Sociobiology, 61(11), 1765-1770. https://doi.org/10.1007/s00265-007-0409-z

Griffiths, S. W. (2003). Learned recognition of conspecifics by fishes. Fish and Fisheries, 4(3), 256-268. https://doi.org/10.1046/j.1467-2979.2003.00129.x

Griffiths, S. W., \& Magurran, A. E. (1997). Familiarity in schooling fish: how long does it take to acquire? Animal Behaviour, 53(5), 945-949. https://doi.org/10.1006/anbe.1996.0315

Griffiths, S. W., \& Magurran, A. E. (1999). Schooling decisions in guppies (Poecilia reticulata) are based on familiarity rather than kin recognition by phenotype matching. Behavioral Ecology and Sociobiology, 45(6), 437-443. https://doi.org/10.1007/s002650050582

Hamilton, W. D. (1964). The genetical evolution of social behaviour. I. Journal of Theoretical Biology, 7(1), 1-16. https://doi.org/10.1016/0022-5193(64)90038-4

Hamilton, W. D. (1971). Geometry for the selfish herd. Journal of Theoretical Biology, 31(2), 295-311. https://doi.org/10.1016/0022-5193(71)90189-5

Hennessy, M. B., Hornschuh, G., Kaiser, S., \& Sachser, N. (2006). Cortisol responses and social buffering: A study throughout the life span. Hormones and Behavior, 49(3), 383-390.

https://doi.org/10.1016/j.yhbeh.2005.08.006 
Hesse, S., Anaya-Rojas, J. M., Frommen, J. G., \& Thünken, T. (2015). Kinship reinforces cooperative predator inspection in a cichlid fish. Journal of Evolutionary Biology, 28(11), 2088-2096. https://doi.org/10.1111/jeb.12736

Heubel, K. U., \& Plath, M. (2008). Influence of male harassment and female competition on female feeding behaviour in a sexual-asexual mating complex of mollies Poecilia mexicana, $P$. formosa. Behavioral Ecology and Sociobiology, 62(11), 1689-1699. https://doi.org/10.1007/s00265-008-05971

Hoare, D. J., Krause, J., Peuhkuri, N., \& Godin, J.-G. J. (2000). Body size and shoaling in fish. Journal of Fish Biology, 57(6), 1351-1366. https://doi.org/10.1111/j.1095-8649.2000.tb02217.x

Höjesjö, J., Johnsson, J. I., Petersson, E., \& Järvi, T. (1998). The importance of being familiar: individual recognition and social behavior in sea trout (Salmo trutta). Behavioral Ecology, 9(5), 445451. https://doi.org/10.1093/beheco/9.5.445

Johnsson, J. I. (1997). Individual Recognition Affects Aggression and Dominance Relations in Rainbow Trout, Oncorhynchus mykiss. Ethology, 103(4), 267-282. https://doi.org/10.1111/j.14390310.1997.tb00017.x

Kelley, J. L., Graves, J. A., \& Magurran, A. E. (1999). Familiarity breeds contempt in guppies. Nature, 401(6754), 661-662. https://doi.org/10.1038/44314

Kerth, G., \& König, B. (1999). Fission, fusion, and nonrandom associations in female Bechstein's bats (Myotis bechsteinii). Behaviour, 136(9), 1187-1202. https://doi.org/10.1163/156853999501711

Killen, S. S., Marras, S., Nadler, L., \& Domenici, P. (2017). The role of physiological traits in assortment among and within fish shoals. Phil. Trans. R. Soc. B, 372(1727), 20160233.

https://doi.org/10.1098/rstb.2016.0233

Kiyokawa, Y., Honda, A., Takeuchi, Y., \& Mori, Y. (2014). A familiar conspecific is more effective than an unfamiliar conspecific for social buffering of conditioned fear responses in male rats. Behavioural Brain Research, 267, 189-193. https://doi.org/10.1016/j.bbr.2014.03.043

Krause, J., Reeves, P., \& Hoare, D. (1998). Positioning behaviour in roach shoals: the role of body length and nutritional state. Behaviour, 135(8/9), 1031-1039.

Krause, J., \& Ruxton, G. D. (2002). Living in groups. OUP Oxford.

Laskowski, K. L., Wolf, M., \& Bierbach, D. (2016). The making of winners (and losers): how early dominance interactions determine adult social structure in a clonal fish. Proc. R. Soc. B, 283(1830), 20160183. https://doi.org/10.1098/rspb.2016.0183

Lee-Jenkins, S. S. Y., \& Godin, J.-G. J. (2013). Concurrent effects of familiarity and kinship on social affiliations in convict cichlid (Amatitlania siquia) young. Behaviour, 150(8), 895-919.

https://doi.org/10.1163/1568539X-00003084 
Magurran, A. E., \& Pitcher, T. J. (1987). Provenance, shoal size and the sociobiology of predatorevasion behaviour in minnow shoals. Proc. R. Soc. Lond. B, 229(1257), 439-465. https://doi.org/10.1098/rspb.1987.0004

Makowicz, A. M., \& Schlupp, I. (2015). Effects of female-female aggression in a sexual/unisexual species complex. Ethology, 121(9), 903-914. https://doi.org/10.1111/eth.12406

Makowicz, A. M., Tiedemann, R., Steele, R. N., \& Schlupp, I. (2016). Kin recognition in a clonal fish, Poecilia formosa. PLOS ONE, 11(8), e0158442. https://doi.org/10.1371/journal.pone.0158442

Merkle, J. A., Sigaud, M., \& Fortin, D. (2015). To follow or not? How animals in fusion-fission societies handle conflicting information during group decision-making. Ecology Letters, 18(8), 799-806. https://doi.org/10.1111/ele.12457

Metcalfe, N. B., \& Thomson, B. C. (1995). Fish recognize and prefer to shoal with poor competitors. Proc. R. Soc. Lond. B, 259(1355), 207-210. https://doi.org/10.1098/rspb.1995.0030

Nakagawa, S., \& Schielzeth, H. (2013). A general and simple method for obtaining R2 from generalized linear mixed-effects models. Methods in Ecology and Evolution, 4(2), 133-142. https://doi.org/10.1111/j.2041-210x.2012.00261.x

Parzefall, J. (1989). Sexual and aggressive behaviour in species hybrids of Poecilia mexicana and Poecilia velifera (Pisces, Poeciliidae). Ethology, 82(2), 101-115. https://doi.org/10.1111/j.14390310.1989.tb00491.x

Peuhkuri, N. (1997). Size-assortative shoaling in fish: the effect of oddity on foraging behaviour. Animal Behaviour, 54(April 1996), 271-8. https://doi.org/10.1006/anbe.1996.0453

Pinheiro, J., Bates, D., DebRoy, S., \& Sarkar, D. (2018). nlme: Linear and Nonlinear Mixed Effects Models. R package version 3.1-137.

Pitcher, T. J., Magurran, A. E., \& Edwards, J. I. (1985). Schooling mackerel and herring choose neighbours of similar size. Marine Biology, 86(3), 319-322. https://doi.org/10.1007/BF00397518

Ranta, E., \& Lindström, K. (1990). Assortative schooling in three-spined sticklebacks? Annales Zoologici Fennici, 27(2), 67-75.

Reader, S. M. (2014). Causes of individual differences in animal exploration and search. Topics in Cognitive Science, 7(3), 451-468. https://doi.org/10.1111/tops.12148

Schartl, M., Wilde, B., Schlupp, I., \& Parzefall, J. (1995). Evolutionary origin of a phartenoform, the amayon molly Poecilia fomosa, on the basis of a molecular geneology. Evolution; International Journal of Organic Evolution, 49(5), 827-835. https://doi.org/10.1111/j.1558-5646.1995.tb02319.x

Schlupp, I. (2009). Behavior of fishes in the sexual/unisexual mating system of the amazon molly (Poecilia formosa). In Advances in the Study of Behavior (Vol. 39, pp. 153-183). Academic Press. https://doi.org/10.1016/S0065-3454(09)39005-1 
Schlupp, I., \& Ryan, M. J. (1996). Mixed-species shoals and the maintenance of a sexual-asexual mating system in mollies. Animal Behaviour, 52(5), 885-890.

https://doi.org/10.1006/anbe.1996.0236

Schlupp, Ingo, Parzefall, J., \& Schartl, M. (2002). Biogeography of the Amazon molly, Poecilia formosa. Journal of Biogeography, 29(1), 1-6. https://doi.org/10.1046/j.1365-2699.2002.00651.x

Smith, J. E., Kolowski, J. M., Graham, K. E., Dawes, S. E., \& Holekamp, K. E. (2008). Social and ecological determinants of fission-fusion dynamics in the spotted hyaena. Animal Behaviour, 76(3), 619-636. https://doi.org/10.1016/j.anbehav.2008.05.001

Sogard, S. M. (1997). Size-selective mortality in the juvenile stage of teleost fishes: a review. Bulletin of Marine Science, 3(60), 1129-1157.

Strandburg-Peshkin, A., Farine, D. R., Crofoot, M. C., \& Couzin, I. D. (2017). Habitat and social factors shape individual decisions and emergent group structure during baboon collective movement. ELife, 6. https://doi.org/10.7554/eLife.19505

Swaney, W., Kendal, J., Capon, H., Brown, C., \& Laland, K. N. (2001). Familiarity facilitates social learning of foraging behaviour in the guppy. Animal Behaviour, 62(3), 591-598. https://doi.org/10.1006/anbe.2001.1788

Thünken, T., Hesse, S., Bakker, T. C. M., \& Baldauf, S. A. (2016). Benefits of kin shoaling in a cichlid fish: familiar and related juveniles show better growth. Behavioral Ecology, 27(2), 419-425. https://doi.org/10.1093/beheco/arv166

Utne-Palm, A. C., \& Hart, P. J. B. (2000). The effects of familiarity on competitive interactions between threespined sticklebacks. Oikos, 91(2), 225-232. https://doi.org/10.1034/j.16000706.2000.910203.x

Walsh, R. N., \& Cummins, R. A. (1976). The Open-Field Test: a critical review. Psychological Bulletin, 83(3), 482-504.

Ward, A. J. W., \& Hart, P. J. B. (2003). The effects of kin and familiarity on interactions between fish. Fish and Fisheries, 4(4), 348-358. https://doi.org/10.1046/j.1467-2979.2003.00135.x

Ward, A. J. W., \& Hart, P. J. B. (2005). Foraging benefits of shoaling with familiars may be exploited by outsiders. Animal Behaviour, 69(2), 329-335. https://doi.org/10.1016/j.anbehav.2004.06.005

Warren, W. C., García-Pérez, R., Xu, S., Lampert, K. P., Chalopin, D., Stöck, M., ... Schartl, M. (2018). Clonal polymorphism and high heterozygosity in the celibate genome of the Amazon molly. Nature Ecology \& Evolution, 1. https://doi.org/10.1038/s41559-018-0473-y

West, S. A., Pen, I., \& Griffin, A. S. (2002). Cooperation and competition between relatives. Science, 296(5565), 72-75. https://doi.org/10.1126/science.1065507

Wittemyer, G., Douglas-Hamilton, I., \& Getz, W. M. (2005). The socioecology of elephants: analysis of the processes creating multitiered social structures. Animal Behaviour, 69(6), 1357-1371.

https://doi.org/10.1016/j.anbehav.2004.08.018 
502 Table 1 - Results of the model testing the effects of treatment and context on total number 503 of aggressive encounters within a group.

\begin{tabular}{lll}
\hline Effect $^{*}$ & Estimate $\quad$ t-value & \\
\hline $\mathrm{R}^{2}$ & \\
Marginal & 0.43 & \\
Conditional & 0.62 &
\end{tabular}

Fixed effects

Treatment:Context

$4.5936 \quad 0.1006$

Treatment

$16.57263<0.001$

Mid

$10.03399 \quad 0.796096$

High

48.95636

4.187288

Context

$10.56642 \quad 0.0012$

After food

$-24.82609$

$-3.581767$

Fish Size

$-12.35011$

$-1.317861$

2.118555

0.1455

Fish Var

0.02962

1.109517

1.521526

0.2174

\section{Random effects}

Group variance

16.33983

2.40853

0.1317

Residual variance

23.8325 
506 Table 2 - Results of the model testing the effects of treatment on median inter-individual 507 distance within each group.

\begin{tabular}{llll}
\hline Effect & Estimate & t-value & \\
\hline $\mathrm{R}^{2}$ & 0.302 & \\
Marginal & 0.593 &
\end{tabular}

Fixed effects

Treatment:context

$1.824668 \quad 0.4016$

Treatment

$9.189975 \quad 0.0101$

Mid

3.625036

1.480117

High

6.951175

3.024320

Context

$13.90384>0.001$

After food

$-5.68$

1.3721

Fish Size

0.623987

0.3898

1.05012

0.3055

Fish Var

0.013100

2.437828

6.380756

0.0115

\section{Random effect}

Group variance

3.211818

2.312011

0.1284

Residual variance 
510 Figure 1 - Detailed schematic of the experimental procedure. Each treatment had a total of

511 eight housing tanks (four are shown here). Low familiarity groups were handled on week 2

512 and assembled the day before testing; Mid familiarity groups were assembled on week 2 and

513 handled once more the day before testing. High familiarity groups were handled twice

514 before being tested.

Figure 2 - Boxplot of the total number of aggressive encounters among all members of a group within each treatment before (dark grey) and after (white) food addition. Dark lines represent medians, the box the inter-quartile range (IQR) and finally the whiskers are 1.5 times the IQR.

Fig 3 - Amount of time one, two, three or four fish were observed feeding together in each treatment. Dark lines represent medians, the box the inter-quartile range (IQR) and finally the whiskers are 1.5 times the IQR.

515 Fig 4 - Median distance within individuals from a group Before Food (dark grey) and After 516 Eating (white) for each treatment. Dark lines represent medians, the box the inter-quartile 517 range (IQR) and finally the whiskers are 1.5 times the IQR. 


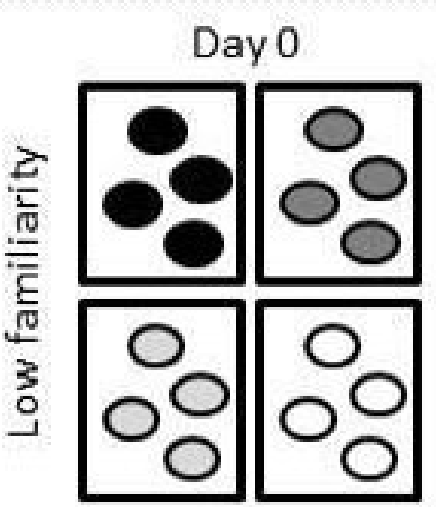

Housing tanks
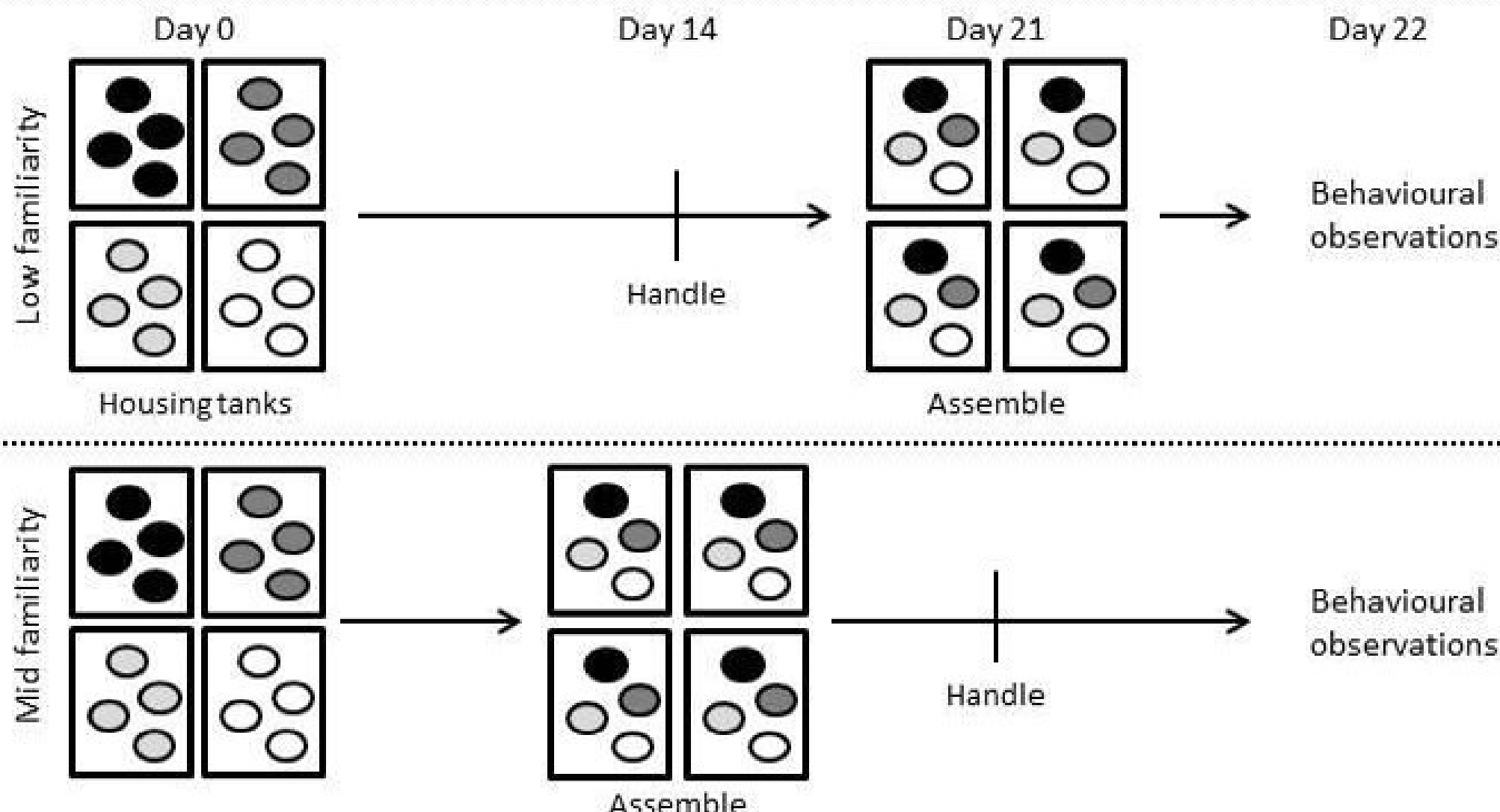

Behavioural observations

Behavioural observations

Handle

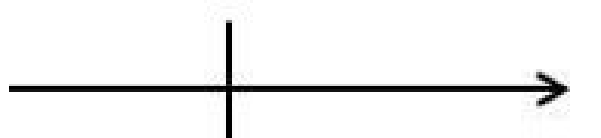

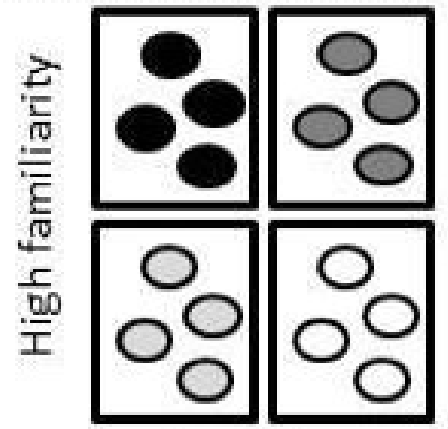

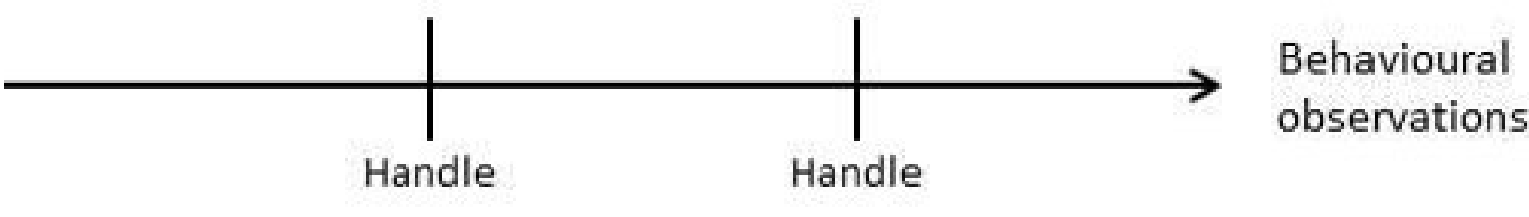

Assemble 


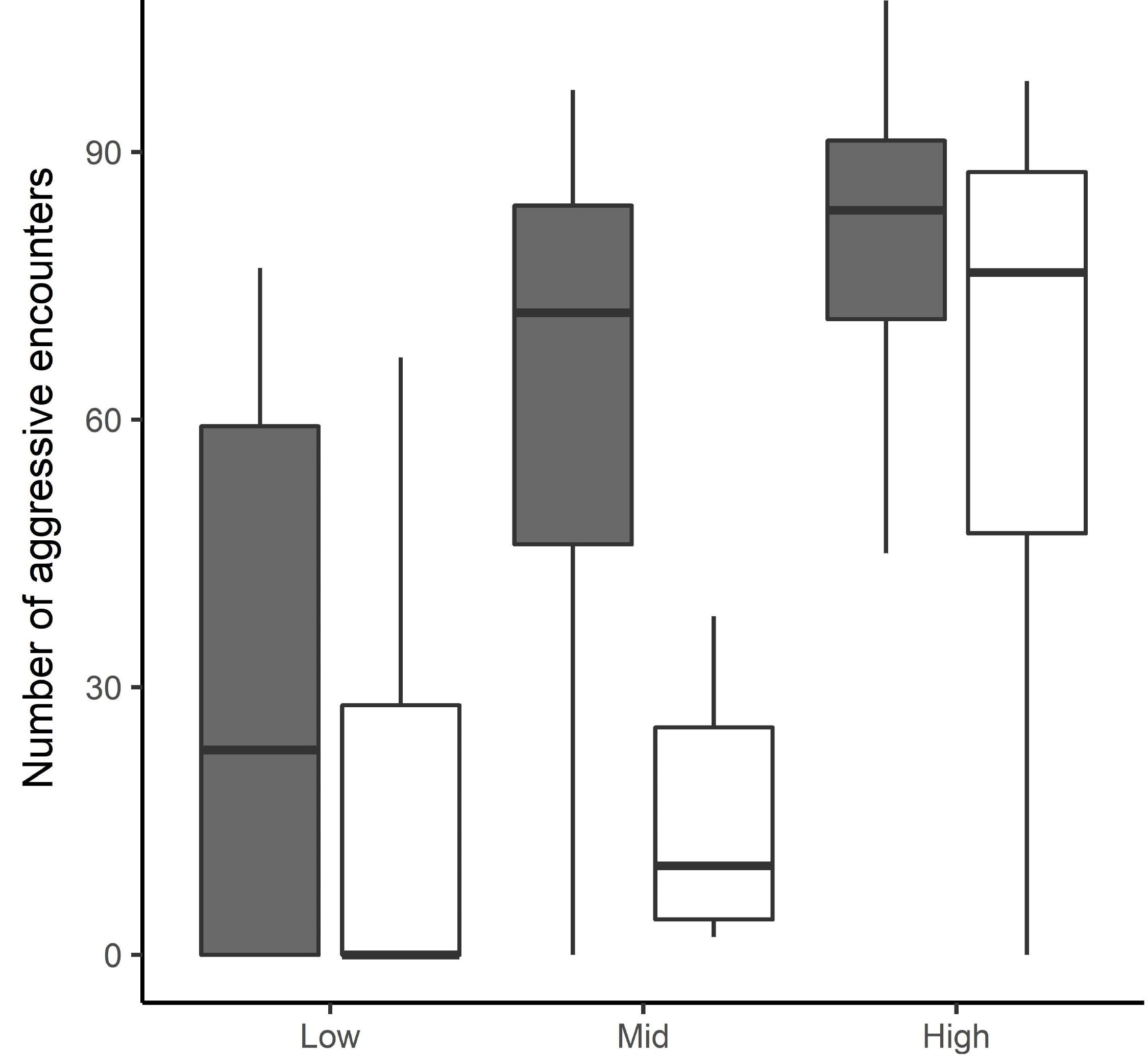

Measurment

ए BF

宁 $A F$ 

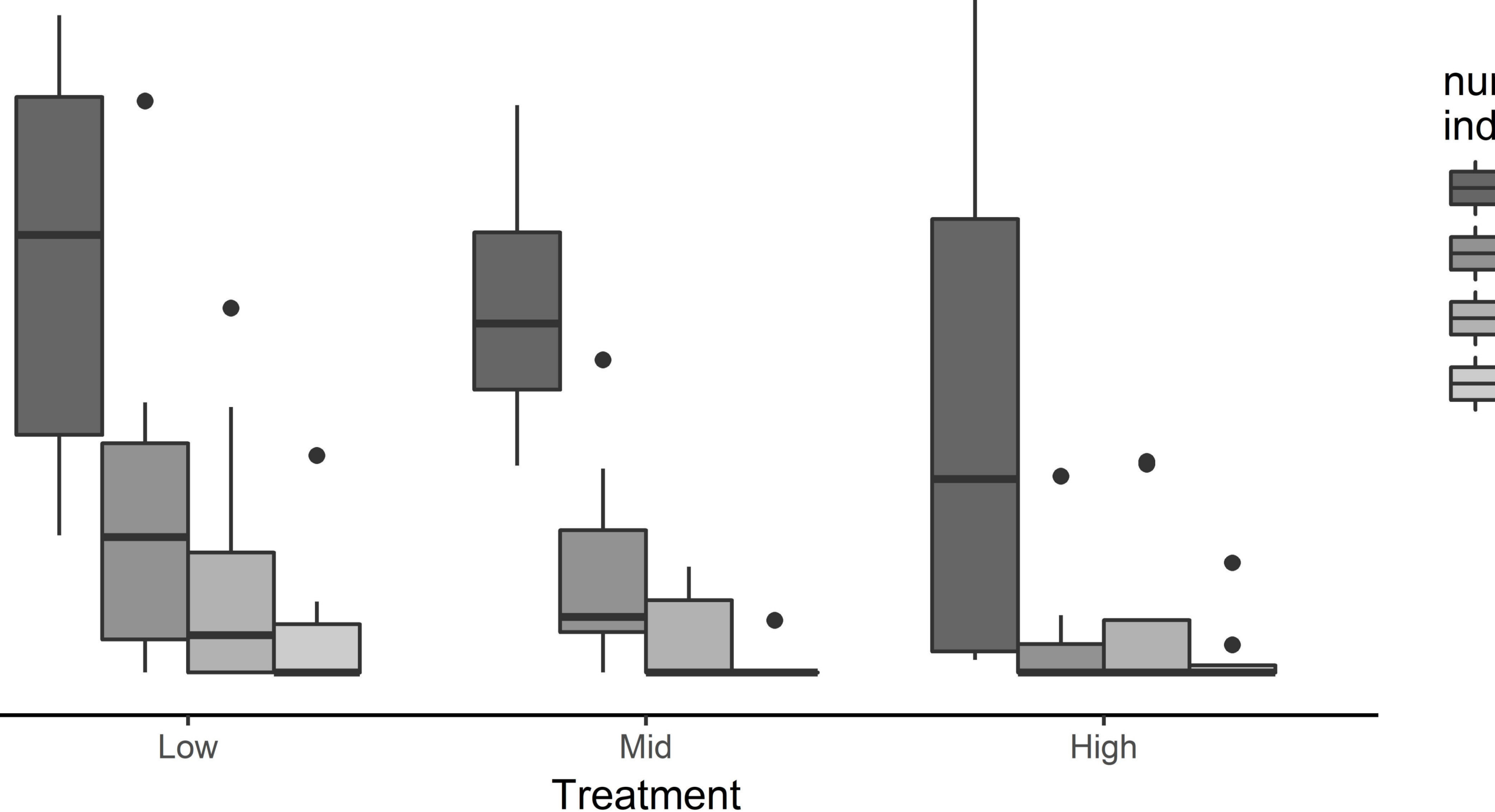


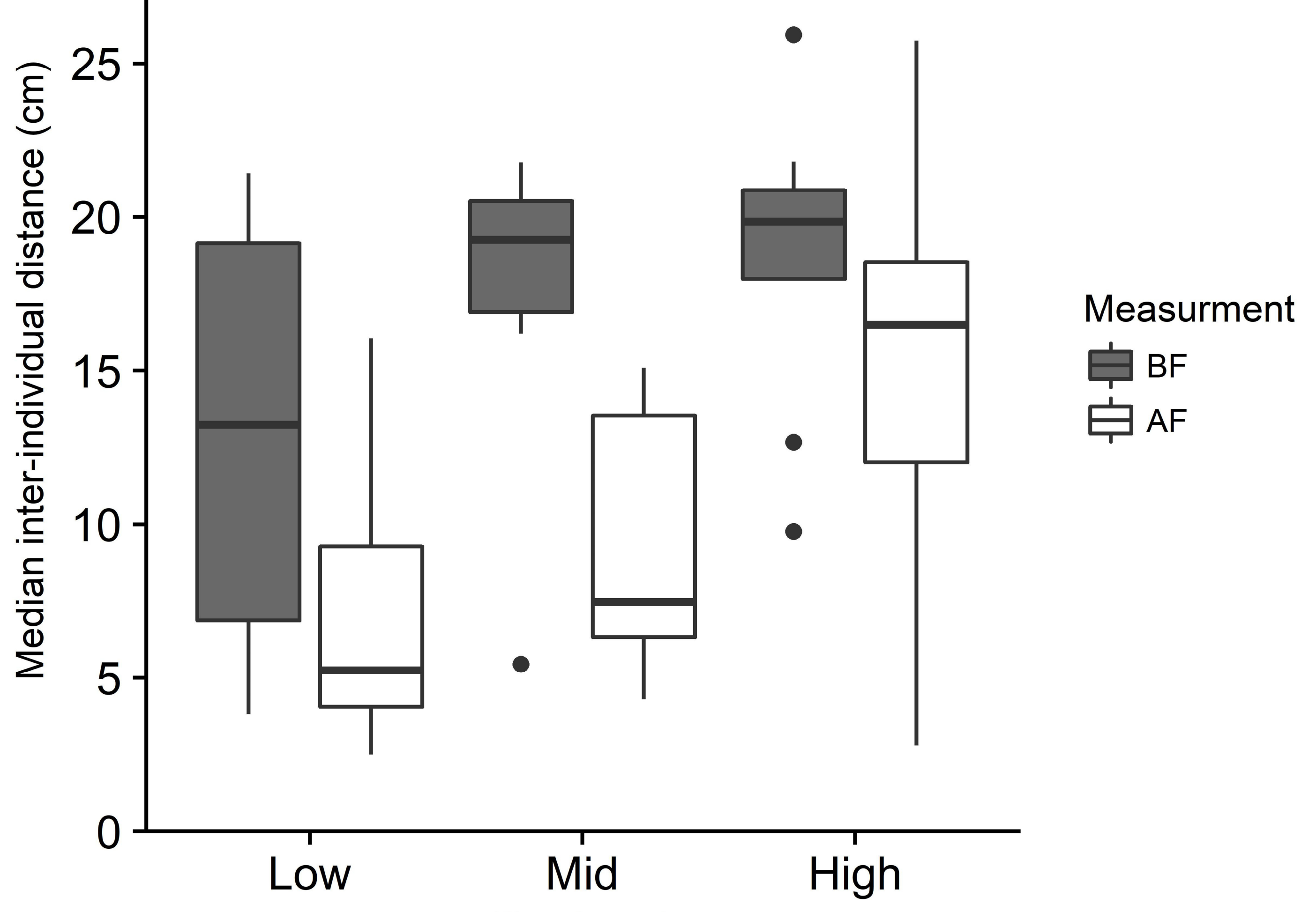

